\title{
The Relationship between the Parameters of Blood Pressure Variability and Arterial Wall Stiffness in Patients with Arterial Hypertension
}

\author{
Nigora B. Tursunova, PhD; Ulugbek I. Nizamov; Ravshanbek D. Kurbanov, PhD, ScD; \\ Gulnoz A. Khamidullaeva, PhD, ScD*; Guzal J. Abdullaeva, PhD, ScD; \\ Alexander B. Shek, $\mathrm{PhD}, \mathrm{ScD}$ \\ Republican Specialized Center of Cardiology, Tashkent, Uzbekistan
}

\begin{abstract}
The purpose of the research was to study the significance of blood pressure variability (BPV) in the assessment of arterial stiffness (AS) in patients with arterial hypertension (AH), and their possible relationship with the indicators of structural and functional remodeling of the myocardium, serum lipid spectrum, and homeostasis system.

Materials and Methods: A total of 138 patients (mean age of 56.7 \pm 12.8 ) with AH were examined. All patients were twice divided consecutively into two groups: one on the basis of age (the age groups $\geq 60$ years and $<60$ years), and another on the basis of the presence or absence of isolated systolic hypertension (ISH). The age groups $\geq 60$ years and $<60$ years did not differ in terms of blood pressure. The ISH and systolic-diastolic hypertension (SDH) subgroups did not significantly differ in sex composition and average 24-h SBP $(131.2 \pm 8.6 \mathrm{~mm} \mathrm{Hg}$ and $137.5 \pm 17.0 \mathrm{mmHg}$, respectively; $P>0.05)$. In the ISH subgroup, average 24-h DBP was significantly lower than in the SDH subgroup: $74.5 \pm 4.8 \mathrm{mmHg}$ and $87.4 \pm 10.9 \mathrm{mmHg}$, respectively $(P=0.000)$. All patients underwent the following examinations: assessment of traditional risk factors, physical examination, clinical and biochemical laboratory methods, 12-lead ECG, echocardiography, 24-hour ABPM, assesment of the AS parameters, and measuring the carotidfemoral pulse wave velocity (PWVcf).

Results: The age group $\geq 60$ years was characterized by a significant increase in AS compared to the age group $<60$ years. In the age group $\geq 60$ years, the levels of daytime and nighttime pulse pressure (PP) and the variability of daytime SBP and PP were significantly higher than in the age group $<60$ years. The increase in AS was associated with an increase in the daytime and nighttime SBP and PP, with the variability of daytime SBP and PP. An increase in AS was also associated with an increase in the degree of the left ventricular myocardium remodeling. In ISH patients, compared to SDH patients, a significant increase in AS was found. ISH patients were characterized by a greater variability in the daily SBP and PP. The level of cardiovascular risk (CVR) in $\mathrm{AH}$ was associated with an increase in the daily variability of SBP, DBP and PP.

Conclusion: In a comprehensive examination of patients with $\mathrm{AH}$, it is advisable to perform ABPM with simultaneous determination of AS parameters. The increased AS and BPV mark the patients belonging to a higher CVR group.(International Journal of Biomedicine. 2019;9(3):197-201.)
\end{abstract}

Key Words: arterial hypertension $\bullet$ ambulatory blood pressure monitoring $\bullet$ arterial stiffness $\bullet$ pulse wave velocity

\section{Abbreviations}

AH, arterial hypertension; ABPM, ambulatory blood pressure monitoring; AIx, augmentation index; AS, arterial stiffness; BP, blood pressure; BPV, blood pressure variability; ISH, isolated systolic hypertension; LVESD, left ventricular end-systolic dimension; LVESV, left ventricular end-systolic volume; PP, pulse pressure; PWV, pulse wave velocity; RoR, rate of rise; SDH, systolic-diastolic hypertension.

\section{Introduction}

In the 21 st century, hypertension remains the major preventable cause of cardiovascular disease and all-cause death globally. ${ }^{(1,2)}$ Large artery stiffening is the most important pathophysiological determinant of isolated systolic hypertension (ISH) and age-dependent increase in pulse pressure (PP). ${ }^{(3,4)}$ The pulse wave velocity (PWV) and the changes in the pulse wave reflections, quantified as augmentation index (AIx), are parameters of arterial stiffness (AS). ${ }^{(5)}$ 
According to $2018 \mathrm{ESC} / \mathrm{ESH}$ guidelines for the management of $\mathrm{AH}$, carotid-femoral PWV is the gold standard for measuring large $\mathrm{AS}^{(3,6)} \mathrm{A}$ growing number of studies have demonstrated the association between AS and stroke, coronary artery disease, dissecting aortic aneurysms, and overall mortality from cardiovascular diseases. ${ }^{(7-9)}$ The additive value of PWV above and beyond traditional risk factors, including SCORE and the Framingham risk score, has been suggested by several studies. ${ }^{(10)}$ There are several devices available for the noninvasive measurement of the PWV and AIx.

In recent years, there has been a tendency to include AS determination algorithms in blood pressure monitoring devices, but the daily dynamics of AS has not been studied enough. ${ }^{(11)}$ Controversial questions remain about the role of dyslipidemia in the genesis of AS, as well as the effect of vascular remodeling on the structural and functional state of the myocardium. Based on the foregoing, the purpose of the research was to study the significance of BPV in the assessment of $\mathrm{AS}$ in patients with $\mathrm{AH}$, and their possible relationship with the indicators of structural and functional remodeling of the myocardium, serum lipid spectrum, and homeostasis system.

\section{Materials and Methods}

Patients for the study were recruited on the basis of the Republican Specialized Scientific-Practical Center for Cardiology in the departments of Coronary Heart Disease and Arterial Hypertension. A total of 138 patients were examined and $106(77 \%)$ were diagnosed with $\mathrm{AH}$. The patients were aged from 36 to 82 years (mean age of $56.7 \pm 12.8$ ). Among the surveyed, men accounted for $52 \%$, women $48 \%$.

The study protocol was reviewed and approved by the Ethics Committee of the Republican Specialized Centre of Cardiology. All participants provided the written informed consent.

Inclusion criteria were the presence of $\mathrm{AH}$ or suspicion of AH. Exclusion criteria were symptomatic hypertension; valvular heart disease, acute coronary syndrome, chronic heart failure (NYHA FC $>$ III), cardiac arrhythmia, history of stroke and myocardial infarction within previous 12 months, occlusive peripheral arterial disease, renal impairment, diabetes mellitus, severe co-morbidities, orthostatic hypotension, conditions requiring hormone steroid therapy or the appointment of anticoagulants, cancer and other pathologies that can affect the state of peripheral arteries.

The structure of the diagnosis of patients with $\mathrm{AH}$ was as follows: AH Grades 1, 2 and 3 were found in 4.7\%, 38\%, and $57.3 \%$, respectively. AH Stages 1, 2 and 3 were detected in $9 \%, 63 \%$ and $28 \%$ of cases, respectively. In $28 \%$ of patients with $\mathrm{AH}$, stable angina functional class II was detected.

Cumulative risk (CR) of heart attacks, strokes and fatal cardiovascular complications was as follows: a low CR - in $0 \%$ of cases, a medium CR - in 19\%, a high CR - in $21 \%$, and a very high $\mathrm{CR}-$ in $60 \%$.

The patients included in the study were twice divided consecutively into two groups: one on the basis of age (the age groups $\geq 60$ years and $<60$ years), and another on the basis of the presence or absence of ISH.
The age groups $\geq 60$ years and $<60$ years did not differ in terms of BP: average 24-h SBP was $129.3 \pm 14.7 \mathrm{mmHg}$ and $136.5 \pm 18.9 \mathrm{mmHg}$, respectively, and average $24-\mathrm{h}$ DBP was $81.9 \pm 11.5 \mathrm{mmHg}$ and $81.0 \pm 10.3 \mathrm{mmHg}$, respectively, $P<0.05$ in both cases. In the age groups $<60$ years and $>60$ years, there were $56 \%$ and $41 \%$ men, respectively, and $44 \%$ and $59 \%$ women, respectively. Thus, the sex composition of the groups did not differ.

The ISH subgroup included 19 patients (58\% women and $42 \%$ men) with mean age of $55.32 \pm 11.6$ years, which was not statistically different from the SDH subgroup-56.9 \pm 9.9 years $(P>0.05)$. The SDH subgroup included 87 patients $(34 \%$ women and $66 \%$ men). The ISH and SDH subgroups did not significantly differ in sex composition and average 24-h SBP $(131.2 \pm 8.6 \mathrm{mmHg}$ and $137.5 \pm 17.0 \mathrm{mmHg}$, respectively; $P>0.05)$. In the ISH subgroup, average 24-h DBP was significantly lower than in the SDH subgroup: $74.5 \pm 4.8$ $\mathrm{mmHg}$ and $87.4 \pm 10.9 \mathrm{mmHg}$, respectively $(P=0.000)$.

All patients underwent the following examinations: assessment of traditional risk factors, physical examination, clinical and biochemical laboratory methods, 12-lead ECG, echocardiography, and 24-hour ABPM. The 24-hour ABPM was performed by the oscillometric method using an XAIMEDICA device and «Kardiosens» software (LLC KhDAVP, Ukraine). ABPM was performed according to the International recommendations.

We implemented the algorithm for analyzing the AS parameters using the SphygmoCor device (AtCor Medical, Australia), which sequentially records pulse waves with a highprecision applanation tonometer applied to the proximal artery (carotid artery) and with a short time interval to the distal artery (femoral artery), and simultaneously recorded an ECG.

The carotid-femoral pulse wave velocity (PWVcf) was calculated using the time of the wave passing between the registration points determined by the $\mathrm{R}$ wave on the ECG. To do this, we determined the time between the $\mathrm{R}$ wave on the ECG and the occurrence of pulsation. ${ }^{(12-14)}$ In addition, such indicators as the central SBP (SBPc), central DBP (DBPc), central PP (PPc), aortic augmentation (AA), and AIx were taken into account.

Echocardiography was carried out according to the recommendations of the American Society of Echocardiography ${ }^{(15)}$ in M- and B-modes using Philips EnVisor C Ultrasound Machine (the Netherlands). The following parameters were measured and calculated: IVST, PWT, LVEDD, LVESD, EF, LVEVD, LVESV, and LVM (LVM was calculated using the formula R. Devereux. ${ }^{(16)}$ LVM was indexed to body surface area (LVMI). Left ventricular hypertrophy $(\mathrm{LVH})$ was defined as LVMI of $>95 \mathrm{~g} / \mathrm{m}^{2}$ (for women) and $>115 \mathrm{~g} / \mathrm{m}^{2}$ (for men). ${ }^{(3)}$

Statistical analysis was performed using the statistical software «Statistica» (v6.0, StatSoft, USA). Baseline characteristics were summarized as frequencies and percentages for categorical variables and as mean \pm standard deviation (SD) for continuous variables. The Mann-Whitney $\mathrm{U}$ Test was used to compare the differences between the two independent groups (for nonparametric data). Spearman's rank correlation coefficient was calculated to measure the strength and direction of the relationship between two variables. We 
used the McNemar chi-square tests to compare discordance of two dichotomous data A probability value of $P \leq 0.05$ was considered statistically significant.

\section{Results and Discussion}

In the age group $\geq 60$ years, an increase in the levels of $\mathrm{SBPc}, \mathrm{PPc}$ and Aix was revealed. In this group, the levels of SBPc, PPc and Aix were $169.7 \pm 11.8 \mathrm{mmHg}, 75.1 \pm 10.1 \mathrm{mmHg}$ and $34.9 \pm 6.8 \%$ compared to $153.8 \pm 9.7 \mathrm{mmHg}(P=0.001), 61.8 \pm 5.1$ $\mathrm{mmHg}(P=0.05)$, and $27.6 \pm 4.3 \%(P=0.05)$ in age group $<60$ years, respectively. In addition, we found a significant increase in the index of PWV up to $13.7 \pm 1.64 \mathrm{~m} / \mathrm{s}$, compared to $11.2 \pm 1.46$ $\mathrm{m} / \mathrm{s}$ in the age group $<60$ years $(P=0.002)$. The detected increase in AS in the group of older patients fits well with literature data. ${ }^{(17-19)}$

The results of ABPM in the two age groups are presented in Table 1 . In the age group $\geq 60$ years, the levels of PP, daytime SBP variability and daytime PP variability were significantly higher than in the age group $<60$ years. The results of ABPM are consistent with the literature data, which also show an increased BPV in older patients. ${ }^{(20)}$

Table 1.

The results of $A B P M$ in the two age groups

\begin{tabular}{|l|c|c|c|}
\hline \multicolumn{1}{|c|}{ Indexes } & $\geq 60$ years & $<60$ years & $\mathrm{P}$ \\
\hline $\begin{array}{l}\text { Daytime SBP variability, } \\
\text { mmHg }\end{array}$ & $15.84 \pm 5.43$ & $10.97 \pm 2.11$ & 0.008 \\
\hline Average PP, mmHg & $59.15 \pm 11.4$ & $45.94 \pm 7.63$ & 0.003 \\
\hline $\begin{array}{l}\text { Minimum daytime PP, } \\
\text { mmHg }\end{array}$ & $38.32 \pm 8.59$ & $33.11 \pm 6.99$ & 0.013 \\
\hline $\begin{array}{l}\text { Average daytime PP, } \\
\text { mmHg }\end{array}$ & $56.09 \pm 12.11$ & $47.53 \pm 7.75$ & 0.002 \\
\hline $\begin{array}{l}\text { Maximum daytime PP, } \\
\text { mmHg }\end{array}$ & $76.68 \pm 18.3$ & $66.78 \pm 12.88$ & 0.034 \\
\hline $\begin{array}{l}\text { Average nighttime PP, } \\
\text { mmHg }\end{array}$ & $54.78 \pm 16.25$ & $45.67 \pm 7.22$ & 0.018 \\
\hline $\begin{array}{l}\text { Maximum nighttime PP, } \\
\text { mmHg }\end{array}$ & $67.22 \pm 18.35$ & $55.84 \pm 11.53$ & 0.009 \\
\hline $\begin{array}{l}\text { Daytime PP variability, } \\
\text { mmHg }\end{array}$ & $9.56 \pm 3.16$ & $7.59 \pm 2.19$ & 0.016 \\
\hline
\end{tabular}

The results of the correlation analysis are presented in Table 2. AIx and PWV (indicators of AS) directly correlated with values of SBP and PP, as well as their variability, in ABPM.

In the age group $\geq 60$ years, fractional shortening was significantly lower $(31.7 \pm 1.9 \%$ and $35.5 \pm 2.6 \%$, respectively, $P=0.008)$ and LVESV significantly greater $(70.2 \pm 18.3 \mathrm{ml}$ and $54.7 \pm 8.0 \mathrm{ml}$, respectively, $P=0.02$ ) than in the age group $<60$ years. LVPWT also increases with age $(\mathrm{R}=0.40, P=0.02)$.

Analysis of the relationships between parameters of daily oscillometry and echocardiography data showed a significant correlation for PWV with IVST ( $\mathrm{R}=0.41, P=0.02)$, LVPWT $(\mathrm{R}=0.46, P=0.009)$ and LVESV $(\mathrm{R}=0.51, P=0.003)$.
Table 2.

Correlations between $A S$ and ABPM parameters

\begin{tabular}{|l|c|c|l|c|c|}
\hline \multicolumn{1}{|c|}{ Indexes } & $\mathrm{R}$ & $\mathrm{P}$ & \multicolumn{1}{|c|}{ Indexes } & $\mathrm{R}$ & $\mathrm{P}$ \\
\hline $\begin{array}{l}\text { AIx and Average } \\
\text { daytime SBP }\end{array}$ & 0.56 & 0.000 & $\begin{array}{l}\text { PWV and Average } \\
\text { daytime SBP }\end{array}$ & 0.61 & 0.001 \\
\hline $\begin{array}{l}\text { AIx and Minimum } \\
\text { daytime SBP }\end{array}$ & 0.42 & 0.000 & $\begin{array}{l}\text { PWV and Minimum } \\
\text { daytime SBP }\end{array}$ & 0.40 & 0.000 \\
\hline $\begin{array}{l}\text { AIx and Maximum } \\
\text { daytime SBP }\end{array}$ & 0.52 & 0.000 & $\begin{array}{l}\text { PWV and Maximum } \\
\text { daytime SBP }\end{array}$ & 0.49 & 0.002 \\
\hline $\begin{array}{l}\text { AIx and Daytime } \\
\text { SBP variability }\end{array}$ & 0.33 & 0.004 & $\begin{array}{l}\text { PWV and Daytime } \\
\text { SBP variability }\end{array}$ & 0.54 & 0.002 \\
\hline $\begin{array}{l}\text { AIx and Average } \\
\text { nighttime SBP }\end{array}$ & 0.28 & 0.018 & $\begin{array}{l}\text { PWV and Average } \\
\text { nighttime SBP }\end{array}$ & 0.30 & 0.01 \\
\hline $\begin{array}{l}\text { AIx and Minimum } \\
\text { nighttime SBP }\end{array}$ & 0.29 & 0.012 & $\begin{array}{l}\text { PWV and Minimum } \\
\text { nighttime SBP }\end{array}$ & 0.36 & 0.01 \\
\hline $\begin{array}{l}\text { AIx and Maximum } \\
\text { nighttime SBP }\end{array}$ & 0.27 & 0.025 & $\begin{array}{l}\text { PWV and Maximum } \\
\text { nighttime SBP }\end{array}$ & 0.22 & 0.000 \\
\hline $\begin{array}{l}\text { AIx and } \\
\text { Average PP }\end{array}$ & 0.78 & 0.000 & PWV and Average PP & 0.81 & 0.000 \\
\hline $\begin{array}{l}\text { AIx and Minimum } \\
\text { daytime PP }\end{array}$ & 0.53 & 0.000 & $\begin{array}{l}\text { PWV and } \\
\text { Average 24- h SBP }\end{array}$ & 0.64 & 0.000 \\
\hline $\begin{array}{l}\text { AIx and Maximum } \\
\text { daytime PP }\end{array}$ & 0.65 & 0.000 & $\begin{array}{l}\text { PWV and } \\
\text { Minimum daytime PP }\end{array}$ & 0.59 & 0.000 \\
\hline $\begin{array}{l}\text { AIx and Minimum } \\
\text { nighttime PP }\end{array}$ & 0.48 & 0.000 & $\begin{array}{l}\text { PWV and } \\
\text { Maximum daytime PP }\end{array}$ & 0.66 & 0.000 \\
\hline $\begin{array}{l}\text { AIx and Average } \\
\text { nighttime PP }\end{array}$ & 0.65 & 0.000 & $\begin{array}{l}\text { PWV and Minimum } \\
\text { nighttime PP }\end{array}$ & 0.54 & 0.000 \\
\hline $\begin{array}{l}\text { AIx and Maximum } \\
\text { nighttime PP }\end{array}$ & 0.63 & 0.000 & $\begin{array}{l}\text { PWV and } \\
\text { Average nighttime PP }\end{array}$ & 0.61 & 0.000 \\
\hline $\begin{array}{l}\text { AIx and Daytime } \\
\text { PP variability }\end{array}$ & 0.48 & 0.000 & $\begin{array}{l}\text { PWV and Maximum } \\
\text { nighttime PP }\end{array}$ & 0.68 & 0.000 \\
\hline SBP RoR & $\begin{array}{l}\text { PWV and Nighttime } \\
\text { PP variability }\end{array}$ & 0.29 & 0.001 \\
\hline PWV and \\
Daytime PP variability
\end{tabular}

There were no significant correlations between the indices of AS and plasma lipid spectrum in the study groups.

In the group of patients with ISH, compared to patients with $\mathrm{SDH}$, the PWV value was significantly greater $(14.5 \pm 2.29 \mathrm{~m} / \mathrm{s}$ and $12.7 \pm 2.9 \mathrm{~m} / \mathrm{s} ; P=0.001)$. In addition, a significant increase in AIx up to $39.9 \pm 4.81 \%$, compared to $31.2 \pm 5.55 \%$, was revealed $(P=0.04)$. The results of ABPM in the groups of patients with ISH and SDH are presented in Table 3. The revealed patterns of the dynamics of SBP, DBP and PP in these groups are regular and follow from the definition of ISH. At the same time, the increase in the variability of the daytime SBP and PP in the ISH group, compared to the SDH subgroup, was poorly discussed in the literature. 
Among the studied parameters of the coagulogram, the level of fibrinogen was significantly greater in the ISH subgroup, compared to the SDH subgroup: $4.3 \pm 1.1 \mathrm{~g} / 1$ and $2.4 \pm 0.3 \mathrm{~g} / \mathrm{l}$, respectively $(P=0.02)$.

Table 3.

The results of ABPM in the groups of patients with ISH and SDH

\begin{tabular}{|l|c|c|c|}
\hline \multicolumn{1}{|c|}{ Indexes } & ISH & SDH & P \\
\hline $\begin{array}{l}\text { Average daytime DBP, } \\
\text { mmHg }\end{array}$ & $76.54 \pm 5.78$ & $87.29 \pm 11.15$ & 0.001 \\
\hline Daytime DBP load, \% & $8.64 \pm 9.66$ & $43.96 \pm 34.12$ & 0.001 \\
\hline $\begin{array}{l}\text { Daytime SBP variability, } \\
\text { mmHg }\end{array}$ & $15.00 \pm 4.75$ & $11.83 \pm 3.76$ & 0.013 \\
\hline $\begin{array}{l}\text { Average nighttime SBP, } \\
\text { mmHg }\end{array}$ & $113.70 \pm 10.98$ & $129.19 \pm 17.77$ & 0.020 \\
\hline $\begin{array}{l}\text { Average nighttime DBP, } \\
\text { mmHg }\end{array}$ & $63.21 \pm 5.68$ & $79.83 \pm 10.63$ & 0.000 \\
\hline Nighttime SBP load, \% & $20.80 \pm 28.38$ & $58.54 \pm 37.33$ & 0.007 \\
\hline Nighttime DBP load, \% & $11.60 \pm 14.46$ & $66.09 \pm 30.86$ & 0.000 \\
\hline Average PP, mmHg & $56.64 \pm 5.26$ & $50.13 \pm 10.45$ & 0.003 \\
\hline $\begin{array}{l}\text { Daytime PP variability, } \\
\text { mmHg }\end{array}$ & $10.67 \pm 3.36$ & $8.06 \pm 2.31$ & 0.012 \\
\hline Nocturnal SBP fall,\% & $13.20 \pm 5.55$ & $6.32 \pm 4.66$ & 0.013 \\
\hline Nocturnal DBP fall, \% & $15.60 \pm 7.69$ & $9.04 \pm 8.35$ & 0.043 \\
\hline $\begin{array}{l}\text { Average 24- h DBP, } \\
\text { mmHg }\end{array}$ & $73.85 \pm 4.80$ & $87.37 \pm 10.89$ & 0.000 \\
\hline
\end{tabular}

When analyzing the relationship between the degree of cardiovascular risk (CVR) and ABPM indices, a significant direct correlation was found with the daily variability of $\mathrm{SBP}(\mathrm{R}=0.39$, $P=0.009)$, $\mathrm{DBP}(\mathrm{R}=0.29, P=0.03)$ and $\mathrm{PP}(\mathrm{R}=0.35 ; P=0.007)$. In addition, a direct correlation was found between the maximum daytime $\mathrm{PP}$ and the degree of CVR $(\mathrm{R}=\mathrm{O} .38, P=0.004)$.

\section{Conclusion}

The age group $\geq 60$ years is characterized by a significant increase in AS compared to the age group $<60$ years. In the age group $\geq 60$ years, the levels of daytime and nighttime PP and the variability of daytime SBP and PP were significantly higher than in the age group $<60$ years. The increase in AS is associated with an increase in the daytime and nighttime SBP and PP, with the variability of daytime SBP and PP. The relationship between AS and the variability of SBP and PP, as well as the morning SBP RoR, was revealed. An increase in AS is also associated with an increase in the degree of the left ventricular myocardium remodeling (an increase in IVST, PWT, and LVESV). In ISH patients, compared to SDH patients, a significant increase in AS was found. ISH patients were characterized by a greater variability in the daily SBP and PP. In the SDH subgroup of patients, an increase in fibrinogen level was revealed. The level of CVR in AH is associated with an increase in the daily variability of SBP, DBP and PP.

Thus, in a comprehensive examination of patients with arterial hypertension, it is advisable to perform ABPM with simultaneous determination of AS parameters. The increased arterial stiffness and blood pressure variability mark the patients belonging to a higher CVR group.

\section{Competing Interests} interests.

The authors declare that they have no competing

\section{References}

1. Banegas JR, Lopez-Garcia E, Dallongeville J, Guallar E, Halcox JP, Borghi C, et al. Achievement of treatment goals for primary prevention of cardiovascular disease in clinical practice across Europe: the EURIKA study. Eur Heart J. 2011;32(17):2143-52. doi: 10.1093/eurheartj/ehr080.

2. Chow CK, Teo KK, Rangarajan S, Islam S, Gupta R, Avezum A, et al.; PURE Study Investigators. Prevalence, awareness, treatment, and control of hypertension in rural and urban communities in high-, middle-, and low-income countries. JAMA.2013; 310(9):959-68. doi: 10.1001/ jama.2013.184182.

3. Williams B, Mancia G, Spiering W, Agabiti Rosei E, Azizi M, Burnier M, et al.; ESC Scientific Document Group. 2018 ESC/ESH Guidelines for the management of arterial hypertension. Eur Heart J. 2018;39(33):3021-3104. doi: 10.1093/eurheartj/ehy339.

4. Laurent S, Cockcroft J, Van Bortel L, Boutouyrie P, Giannattasio C, Hayoz D, et al.; European Network for Noninvasive Investigation of Large Arteries. Expert consensus document on arterial stiffness: methodological issues and clinical applications. Eur Heart J. 2006;27(21):2588-605.

5. Mihalcea DJ, Florescu M, Suran BM, Enescu OA, Mincu RI, Magda S, Patrascu N, Vinereanu D. Comparison of pulse wave velocity assessed by three different techniques: Arteriograph, Complior, and Echo-tracking. Heart Vessels. 2016;31:568-77. doi: 10.1007/s00380-015-0632-x.

6. Van Bortel LM, Laurent S, Boutouyrie P, Chowienczyk P, Cruickshank JK, De Backer T, et al.; Artery Society; European Society of Hypertension Working Group on Vascular Structure and Function; European Network for Noninvasive Investigation of Large Arteries. Expert consensus document on the measurement of aortic stiffness in daily practice using carotid-femoral pulse wave velocity. J Hypertens. 2012;30(3):445-8. doi: 10.1097/HJH.0b013e32834fa8b0.

7. Laurent S, Boutouyrie P, Asmar R, Gautier I, Laloux B, Guize L, et al. Aortic stiffness is an independent predictor of all-cause and cardiovascular mortality in hypertensive patients. Hypertension. 2001;37(5):1236-41.

8. Tsivgoulis G, Bogiatzi C, Heliopoulos I, Vadikolias $\mathrm{K}$, Boutati E, Tsakaldimi S, et al. Low ankle-brachial index predicts early risk of recurrent stroke in patients with acute cerebral ischemia. Atherosclerosis. 2012;220(2):407-12. doi: 10.1016/j.atherosclerosis.2011.11.009.

*Corresponding author: Prof. Gulnoz A. Khamidullaeva, PhD, ScD. The Republican Specialized Center of Cardiology, Tashkent,Uzbekistan.E-mail: gulnoz0566@mail.ru 
9. Suzuki J, Sakakibara R, Tomaru T, Tateno F, Kishi M, Ogawa E, et al. Stroke and cardio-ankle vascular stiffness index. J Stroke Cerebrovasc Dis. 2013 Feb;22(2):171-5. doi: 10.1016/j.jstrokecerebrovasdis.2011.07.010.

10. Ben-Shlomo Y, Spears M, Boustred C, May M, Anderson SG, Benjamin EJ, et al. Aortic pulse wave velocity improves cardiovascular event prediction: an individual participant metaanalysis of prospective observational data from 17,635 subjects. J Am Coll Cardiol. 2014;63(7):636-646. doi: 10.1016/j. jacc.2013.09.063.

11. Gosse P, Cipriano C, Bemurat L, Mas D, Lemétayer P, N'Tela G, Clementy J. Prognostic significance of blood pressure measured on rising. J Hum Hypertens. 2001;15(6):413-7.

12. Blacher J, Guerin AP, Pannier B, Marchais SJ, Safar ME, London GM. Impact of aortic stiffness on survival in endstage renal disease. Circulation. 1999;99(18):2434-9.

13. Boutouyrie P. New techniques for assessing arterial stiffness.Diabetes Metab. 2008;34 Suppl 1:S21-6. doi: 10.1016/S1262-3636(08)70099-5.

14. Nazarova OA, Maslennikova OM, Fomin FYu. Evaluation of the elastic properties of blood vessels in the clinic of internal diseases. Ivanovo; 2007. [In Russian].

15. Voigt JU, Pedrizzetti G, Lysyansky P, Marwick TH, Houle
H, Baumann R, et al. Definitions for a common standard for 2D speckle tracking echocardiography: consensus document of the EACVI/ASE/Industry Task Force to standardize deformation imaging. Eur Heart $\mathrm{J}$ Cardiovasc Imaging. 2015;16(1):1-11. doi: 10.1093/ehjci/jeu184.

16. Devereux RB, de Simone G, Ganau A, Roman MJ. Left ventricular hypertrophy and geometric remodeling in hypertension: stimuli, functional consequences and prognostic implications. J Hypertens Suppl. 1994;12(10):S117-27.

17. McVeigh GE, Hamilton PK, Morgan DR. Evaluation of mechanical arterial properties: clinical, experimental and therapeutic aspects. Clin Sci (Lond). 2002;102(1):51-67.

18. Laurent S, Boutouyrie P. Recent advances in arterial stiffness and wave reflection in human hypertension. Hypertension. 2007;49(6):1202-6.

19. Nikitin YuP. New fundamental and applied bases of atherogenesis. Bulletin of SB of RAMS. 2006;(2):6-14. [Article in Russian].

20. Troitskaya EA, Kotovskaya YuV, Kobalava ZhD. High intervisiting blood pressure variability - a possible marker of the severity of cardiovascular disease in patients with arterial hypertension (Abstract of the IV Eurasian Congress of Cardiologists). Eurasian Heart Journal. 2016;(3):47-48. [in Russian]. 